\title{
Turismo alternativo solidário e o Centro Público de Economia Solidária de Itajaí, SC
}

The alternative solidarity tourism and the Public Center for Solidarity Economy of Itajaí, SC

\section{Le tourisme alternatif de la solidarité et le Centre Public de L'economie Solidaire Itajaí, SC}

\author{
El turismo alternativo solidario y el Centro Público de Economia Solidária de Itajaí, SC
}

\author{
Idalina Maria Boni* \\ (idalina@univali.br) \\ Rafaela Vieira** \\ (arquitetura.rafaela@gmail.com)
}

Recebido em 10/04/2015; revisado e aprovado em 14/07/2015; aceito em 30/07/2015

DOI: http://dx.doi.org/10.1590/151870122015211

Resumo: O objetivo deste trabalho foi identificar as experiências do Centro Público de Economia Solidária de
Itajaí (CEPESI) e sua produção relacionada ao turismo. De caráter qualitativo, é uma pesquisa do tipo exploratória
e descritiva. Os resultados apontam que os associados e parceiros do CEPESI demonstraram-se interessados na
associação do turismo à economia solidária, existindo desafios a serem superados.
Palavras-chave: Turismo. Economia solidária. Desenvolvimento local.
Abstract: The objective of this paper was to describe the experiences of the Public Center for Solidarity Economy
of Itajaí (CEPESI) and its production related to tourism. Qualitative, constitutes in a exploratory and descriptive
survey. The results show that members and partners of CEPESI demonstrate their interest in the association of
social economy and tourism, still existing challenges to be overcome.
Key words: Tourism. Solidarity economy. Local development.
Résumé: L'objectif de cette recherche était d'identifier les expériences de le Centre Public de L'economie Solid-
aire Itajaí (CEPESI) et la production liée au secteur touristique. A caractere qualitative, constitue une enquête sur
l'exploratorie et descriptive. Les résultats raportent que les membres et les partenaires CEPESI ont manifesté leurs
intérêts dans l'économie sociale et de l'association touristique, afin surmonter l'osbstacle.
Mots-clés: Tourisme. Économie solidaire. Développement local.
Resumen: El objetivo de la investigación fue describir las experiencias del Centro Público de Economía Solidaria
de Itajaí (CEPESI) y su producción relacionadas al turismo. De carácter cualitativo, se trató de un estudio de tipo
exploratorio y descriptivo. Los resultados demuestran que los miembros y apoyadores de CEPESI tienen interés
en la asociación entre economía social y turismo, pero que hay retos por superar en este sentido.
Palabras clave: Turismo. Economía solidaria. Desarrollo local.

\section{Introdução}

O turismo é uma atividade econômica complexa e multifacetada. Envolve agentes sociais variados que terão diferentes percepções, atitudes e comportamentos durante a visita ao destino. Tem-se, portanto, a necessidade de compreender as possibilidades de se trabalhar o turismo de forma integrada aos valores humanos, ao desenvolvimento local sustentável e à economia solidária.

O turismo alternativo solidário vem sendo tratado como uma oportunidade no âmbito social, econômico e cultural, para proporcionar o desenvolvimento de diversas localidades. Novas propostas de desenvolvi- mento vêm sendo apontadas, e a atividade turística tem sido fim central em grande parte dessas experiências, tendo-se como foco o turismo alternativo.

O turismo alternativo solidário de base comunitária busca se contrapor ao turismo massificado, requerendo menor densidade de infraestrutura e serviços e buscando valorizar uma vinculação situada nos ambientes naturais e na cultura de cada lugar. (BURSZTYN; BARTHOLO; DELAMARO, 2009, p. 86).

Podemos ter também destinos turísticos urbanos que possam se ligar a uma organização da economia solidária e trabalhar atividades voltadas a turismo alternativo. $\mathrm{O}$

\footnotetext{
* Universidade do Vale do Itajaí (UNIVALI), Itajaí, Santa Catarina, Brasil.

** Universidade Regional de Blumenau (FURB), Blumenau, Santa Catarina, Brasil.
} 
turismo alternativo solidário se viabiliza com a mobilização de agentes locais que são parte da cadeia produtiva do turismo e do movimento social organizado. Não é apenas um trabalho ou serviço que deva ser executado pela prefeitura ou pela iniciativa privada para desenvolver a cidade e seu potencial turístico, mas a somatória dos agentes é que faz acontecer o desenvolvimento local, devendo ser planejado esse processo.

Para Hall (2001), o planejamento do turismo requer processos integrados em que haja participação e envolvimento de diversos setores na construção de localidades sustentáveis. Yázigi (2009) afirma que o turismo não se constitui em uma categoria de análise, e seu planejamento deve envolver diferentes setores, demandando ações integradas.

A economia solidária possui princípios fundamentais, não apenas como um instrumento de geração de emprego e renda, mas, principalmente, como fonte de integração e crescimento dos indivíduos, resguardando que seus integrantes usufruam do resultado de maneira igualitária. "A economia solidária se constitui em um conjunto de práticas e estratégias socioeconômico que, ao longo da história humana, [...] manteve viva a possibilidade de uma ordem social baseada sobre a cooperação e a autogestão" (ARROYO, 2013, p. 01).

O Centro Público de Economia Solidária de Itajaí (CEPESI) envolve-se diretamente com a atividade turística, pois sua sede encontra-se implantada no centro da cidade, próximo ao píer turístico de Itajaí, cidade portuária e que está na rota de transatlânticos. Constitui-se em um espaço físico de comercialização, especialmente de produtos artesanais, congregando associados e parceiros de vários municípios da Região Turística da Costa Verde \& Mar e do município de Brusque. Além desse espaço físico, o CEPESI constitui-se em uma estrutura articuladora e mobilizadora da geração de renda coletiva para esta região centro-norte catarinense, que trabalha o comércio justo e a vivência dos princípios da economia solidária.

Portanto passa a ser pertinente discutir o turismo alternativo solidário junto ao CEPESI, com o intuito de compreender como este pode contribuir para o desenvolvimento local sustentável incluindo os princípios da economia solidária. O objetivo foi identificar as experiências do CEPESI e sua produção relacionada ao turismo, visando descrever as possibilidades de articular o trabalho dessa organização ao turismo alternativo solidário.

$\mathrm{O}$ artigo estrutura-se nos seguintes itens: referencial teórico, no qual se apresentam conceitos e articulações entre turismo alternativo solidário e economia solidária; a metodologia adotada; breve caracterização do turismo regional e local; resultados obtidos e considerações finais.

\section{Turismo alternativo solidário e economia solidária: algumas considerações}

Para muitos, turismo é basicamente viajar, ou viver experiências novas e conhecer culturas. O trabalho com turismo nos leva a reconhecer várias demandas envolvidas no atendimento ao turista.

O turismo exige viagem e desencadeia redes de serviços; [...] Os serviços turísticos são processos interativos entre quem oferece e quem procura, uma prestação cada vez mais personalizada ao cliente, com qualidade e informação sobre a clientela, além do uso de tecnologias modernas de informação. (CORIOLANO et al., 2009, p. 15).

O turismo é uma das principais atividades econômicas de serviço, promovida por muitos países em desenvolvimento como estratégia para a redução da pobreza. Diante disso, além do turismo de massa, existe outra forma de organização turística que segue os princípios de respeito, inclusão, solidariedade, sustentabilidade e reúne as comunidades ou grupos com apoio de Organizações NãoGovernamentais (ONGs), turistas conscientes que desejam trabalhar em defesa e no convívio com o meio ambiente, realizando um turismo diferenciado. Existe um fluxo importante para esse eixo conhecido como turismo alternativo solidário, e pode-se perceber que existem turistas para todas as formas de oferta turística.

Visando à distribuição equitativa, esse turismo diferenciado se apresenta como um forte vetor de transformação no qual a ideia central é empreender ações governamentais e privadas no sentido de aproximar e mobilizar pessoas físicas e jurídicas, dispostas a conhecer a realidade das comunidades, dos territórios, objetivando colaborar na melhoria da qualidade de vida das pessoas. $\mathrm{O}$ turismo 
alternativo solidário ou comunitário atua na perspectiva de que o turista se torne um agente social que proporcione mudanças positivas nos locais que visita. Uma parcela crescente da população demanda por produtos e serviços alternativos, querendo conhecer a procedência destes, valorizando as pessoas que os produzem, e esse processo é conhecido como comércio justo.

Crescem e ganham visibilidade na academia, na mídia e no setor público as inúmeras experiências de organização da atividade turística classificadas como Turismo de Base Comunitária, Turismo Comunitário, Solidário, de Conservação, entre outras denominações, em todo o mundo, e em particular na América Latina. (BRASIL, 2010, publicação sem número de páginas).

Os estudos acerca do tema têm crescido, mas ainda há falta de consenso sobre os conceitos, resultado da diversidade das próprias experiências turísticas alternativas solidárias e de base comunitária que ocorrem pelo país, efetivadas por instituições reconhecidas como pioneiras na organização das atividades turísticas alternativas.

Segundo Bartholo, Sansolo e Bursztyn (2009, p. 110), podem-se traçar alguns princípios comuns entre as diversas definições: "autogestão; associativismo e cooperativismo; democratização de oportunidades e benefícios; valorização da cultura local e, principalmente, protagonismo das comunidades locais na gestão da atividade". A Economia Solidária converge neste mesmo sentido dos princípios coletivos:

O princípio da economia solidária é a apropriação coletiva dos meios de produção, a gestão democrática pelos membros das decisões e deliberação coletiva sobre os rumos da produção, a utilização dos excedentes (sobras) e, também, sobre a responsabilidade coletiva quanto aos eventuais prejuízos da organização econômica. (SCHIOCHET, 2012, p. 25).

No Brasil, a economia solidária vem crescendo e se firmando como outra forma de organizar também a economia com o fortalecimento do direito coletivo ao trabalho. Essa forma de organização se expressa via organização de associações, cooperativas, clubes de troca, empresas de autogestão, visando fortalecer a geração de renda e inclusão social. Conta também com a ajuda de políticas públicas e entidades de apoio que buscam fortalecer este trabalho. As definições de economia solidária reforçam os princípios defendidos pelo turismo alternativo solidário ou de base comunitária como vem sendo definido, que deve conduzir o turista a uma forma de solidariedade concreta com os locais visitados.

Baseado nos princípios da economia solidária, o turismo comunitário ou solidário se mostra como alternativa aos projetos de turismo convencional. O turismo comunitário questiona o mito do turismo como gerador de emprego e renda e denuncia as políticas centradas na atração de investimentos que não levam em consideração a participação e o desenvolvimento das comunidades locais. (FONTOURA, 2009, p. 03).

O turismo alternativo solidário, pautado nos princípios da economia solidária, constrói um turismo mais equitativo, reforçando a inclusão social e econômica de organizações e/ou grupos de trabalhadores e trabalhadoras que produzam bens ou serviços, ampliando a renda das famílias, de forma autogestionária. As iniciativas de economia solidária podem incrementar ganhos sociais em termos de autoestima e empoderamento dos empreendimentos, favorecendo a formação para o trabalho autônomo associativo.

Se olharmos de perto, trata-se do desejo de um diálogo de sentidos entre os visitantes e os visitados, que procura abrir um caminho através dos escombros que o turismo de massa uniformizador deixa para trás. (ZAQUAL, 2009, p. 59).

Esses escombros só podem ser enfrentados com um olhar intrínseco ao local, às comunidades e o envolvimento das pessoas.

O desenvolvimento local é uma oportunidade de possibilitar o crescimento em todos os aspectos da vida humana. As diversas iniciativas do turismo alternativo solidário são fundamentadas nos modos de vida local.

Este tipo de organização e oferta do produto turístico possui elementos comuns como a busca da construção de um modelo alternativo de desenvolvimento turístico baseado na autogestão, no associativismo/ cooperativismo, na valorização da cultura local e, principalmente, no protagonismo das comunidades locais, visando à apropriação, por parte destas, dos benefícios advindos do desenvolvimento do setor. (SILVA; RAMIRO; TEIXEIRA, 2009, p. 362). 
Para Irving (2009), há necessidade de novos modelos para a prática social do turismo que emergem no sentido de buscar promover o desenvolvimento e o protagonismo dos envolvidos.

\section{Percurso metodológico}

De caráter qualitativo, a pesquisa é do tipo exploratória e descritiva e estrutura-se em três etapas: coleta de dados, sistematização das informações, análise com discussão dos resultados. As técnicas de pesquisa utilizadas foram a pesquisa bibliográfica, documental e observação participante.

A pesquisa bibliográfica sobre a temática estudada pautou-se na busca por artigos científicos nos Anais da ANPTUR e em bases de dados como SciELO e EBSCO. É recente a produção acerca do turismo alternativo solidário no Brasil, sendo bastante substancioso embasar reflexões e estudos que contribuam às novas construções, tendo-se identificado como autores-chaves Coriolano et al. (2009), Irving (2009), Maldonado (2009) e Zaqual (2009).

Na pesquisa documental, efetuou-se o levantamento de dados históricos em documentos dos fóruns de Economia Solidária, documentos produzidos por instituições governamentais e do Centro Público de Economia Solidária de Itajaí.

Utilizou-se também a observação participante, definida por Moreira (2002, p. 52) como "uma estratégia de campo que combina ao mesmo tempo a participação ativa com os sujeitos, a observação intensiva em ambientes naturais, entrevistas abertas informais e análise dos dados." Essa técnica foi viabilizada através de entrevistas semiestruturadas com perguntas abertas, gravadas e transcritas, bem como pela vivência de uma das autoras nas atividades do Centro Público, visto que é parte integrante da associação (BONI, 2014).

A observação participante:

Consiste na participação real do pesquisador com a comunidade ou grupo. Ele se incorpora ao grupo, confunde-se com ele. Fica tão próximo quanto um membro do grupo que está estudando e participa das atividades normais deste. (LAKATOS; MARCONI, 1991, p. 194).

Com a observação participante, buscouse compreender como os membros e parceiros identificam o CEPESI e a economia solidária de Itajaí, qual sua visão sobre turismo e turismo alternativo solidário, quais os produtos da cidade e do CEPESI para agregar a atividade turística e as necessidades para essa efetiva articulação como turismo.

Para a compreensão dos resultados das entrevistas, foi usada a técnica de interpretação do Discurso do Sujeito Coletivo (DSC), utilizando-se expressões-chaves e ideias centrais. O DSC "é uma proposta de organização e tabulação de dados qualitativos de natureza verbal, obtidos de depoimentos" (LEFÈVRE; LEFÈVRE, 2000, p. 70). Apresenta os resultados em forma de discurso de uma ou mais pessoas, sintetizados e na primeira pessoa do singular. Optou-se por essa metodologia para análise qualitativa, pois possibilita voz aos indivíduos, destacando a percepção de cada envolvido. vilegiam:

Nesse sentido, destacamos que se pri-

[...] os discursos de cada sujeito reunidos em um discurso único em cada tema tratado, visando capturar as experiências da população estudada por meio das respostas às entrevistas, tornando um discurso único o discurso de muitos. (LEFÈVRE; LEFÈVRE, 2000, p. 16).

Os demais dados levantados foram sistematizados em textos e ilustrações, conforme sua natureza e finalidade, sendo na sequência analisados. Isso possibilitou identificar o estado da arte sobre o tema estudado e as experiências do CEPESI vinculadas ao turismo, contribuindo para descrever as possibilidades de articular o trabalho dessa organização ao turismo alternativo solidário.

\section{Turismo e o contexto regional e local}

O estado de Santa Catarina organizou os planos regionais de turismo, ou macro programas de regionalização do turismo, visando à segmentação e organização do estado para desenvolvimento turístico, como previsto nos Planos Nacionais de Turismo. Nesse processo, o estado catarinense foi dividido em dez destinos turísticos, denominado Caminhos dos Cânions, Caminhos dos Príncipes, Caminhos da Fronteira, Encantos do Sul, Grande Florianópolis, Grande Oeste, Serra Catarinense, Vale Europeu, Vale do Contestado e Costa 
Verde \& Mar.

A região do litoral centro norte catarinense, onde se localiza a Região Turística da Costa Verde \& Mar, é reconhecida por suas belezas naturais e sua significativa representatividade no contexto turístico estadual. $\mathrm{O}$ município de Itajaí está articulado a outros municípios dessa região através da Associação dos Municípios da Foz do Rio Itajaí (AMFRI), que possui o Consórcio Intermunicipal de Turismo Costa Verde \& Mar, o qual pretende em seu escopo facilitar a articulação entre os associados, estabelecer políticas públicas, realizar a divulgação dos municípios associados em feiras e demais meios turísticos, bem como produção de materiais sobre articulação de roteiros, levantamento de dados e planejamento turístico.

A Costa Verde \& Mar, composta pelas destinações de Balneário Camboriú, Balneário Piçarras; Bombinhas; Camboriú; Ilhota; Itajaí; Itapema; Luiz Alves; Navegantes; Penha e Porto Belo, revisou seu Plano Estratégico de Marketing Turístico Integrado (PEMTI) ao longo do ano de 2012, com sua publicação em 2013, através de oficinas internas promovidas pelo Colegiado do Curso de Turismo e Hotelaria da Universidade do Vale do Itajaí (UNIVALI), bem como oficinas em conjunto com o trade turístico, para validar as ações e estratégias, segundo a AMFRI (2013). O PEMTI constitui-se em um instrumento de planejamento que visa subsidiar a continuidade do desenvolvimento da atividade turística, a implementação de novos empreendimentos, o incremento da demanda, além de inserir novos paradigmas de gestão para o turismo que se sustentem no fortalecimento da imagem, consolidação de roteiros turísticos, logística integrada, captação de investidores e estímulo à cultura empreendedora.

Cabe destacar que o PEMTI da Costa Verde \& Mar não faz qualquer referência ao turismo alternativo solidário na região, nem ao Centro Público de Economia Solidária de Itajaí, apesar de destacar o artesanato como ponto forte da cidade.

Os pontos fortes da Costa Verde \& Mar indicados no PEMTI (AMFRI, 2013) fazem referência à constância de população de acadêmicos de cursos de graduação que possuem articulação com a atividade turística. Somado a isso, a abertura de cursos técnicos faz com que a oferta de profissionais qualificados seja uma constante na região. Vale ressaltar a existência de cursos de graduação e tecnologia específicos para as demandas da região, como Logística, Engenharia Naval, Turismo e Hotelaria, Gastronomia, entre outros.

Como pontos fracos da Costa Verde \& Mar, o PEMTI (AMFRI, 2013) identifica que a qualidade de vida no Brasil está melhorando, porém a desigualdade social ainda permanece um problema a ser enfrentado, inclusive na região. A busca por empregos durante a alta temporada continua sendo uma realidade nos municípios da Costa Verde \& Mar, em especial nos municípios litorâneos, que muitas vezes não conseguem absorver essa mão de obra durante o resto do ano, potencializando problemas sociais. As ações sociais direcionadas ao processo migratório continuam sendo uma necessidade para os municípios da região da Costa Verde \& Mar.

Integrante da Costa Verde \& Mar, o município de Itajaí encontra-se em uma região geográfica estratégica do território catarinense sob o ponto de vista logístico e é a sede do CEPESI.

No município situam-se intersecções de importantes rodovias federais (BR 101 e BR 470) e estaduais (SC 412 e SC 486). Além de possuir um porto municipal, está próximo ao porto e ao aeroporto Internacional Ministro Victor Konder, ambos localizados em Navegantes.

Itajaí congrega atividades industriais, comerciais, acadêmicas e turísticas. Sua população, em 2010, era de 183.373 habitantes segundo dados do censo do Instituto Brasileiro de Geografia e Estatística (IBGE, 2010). Na área urbana, concentram-se $96,2 \%$ dos habitantes, sendo a $7^{\mathrm{a}}$ cidade do estado em número de população. Seu Índice de Desenvolvimento Humano Municipal (IDH-M) em 1991 era de 0,588. Em 2000, chegou a 0,688, alcançando, em 2010, um total de 0,795, apontando um aumento desse índice e um bom desempenho.

A economia de Itajaí possui o segundo maior Produto Interno Bruto (PIB) do estado, potencializado pelo porto. Além disso, também é uma cidade universitária, sendo que a UNIVALI se destaca como uma das maiores instituições de ensino do Brasil, com mais de 70 cursos superiores. A cidade possui riquezas culturais, com traços históricos marcantes 
trazidos pelos imigrantes portugueses, alemães e italianos, que também se manifestam em sua arquitetura.

Próximo à sede do CEPESI, há um píer em que atracam cruzeiros marítimos internacionais na região Sul do Brasil. O píer possui estrutura de alfândega e está voltado predominantemente para o turismo de massa, colocando Itajaí na rota turística regional, pois se situa entre cidades constantemente procuradas por turistas: Balneário Camboriú, um dos três destinos turísticos do sul do país, e Penha, conhecida por abrigar um dos maiores Parques Temáticos da América Latina, o Beto Carreiro World.

Itajaí, através da Secretaria de Turismo, vem fomentando discussões a fim de analisar e organizar-se para um maior crescimento da atividade turística na cidade. Por ocasião da comemoração dos 153 anos de fundação da cidade em 2013, foi realizado o Terceiro Fórum Itajaiense de Turismo, visando articular a comunidade no sentido de construir caminhos para essa atividade (ITAJAÍ, 2013). A cidade de Itajaí, SC, apresenta uma estrutura de atendimento do turismo por demanda e vem buscando se firmar no segmento do turismo náutico e cultural.

O turismo náutico caracteriza-se pela utilização de embarcações náuticas com finalidade da movimentação turística. A realização da regata Volvo Ocean Race, em 2012 e 2015, e a regata Jacques Vabre, em 2013, apontam o destaque da cidade neste setor.

Mesmo sendo pouco discutido e com reduzidos dados sobre sua contribuição e movimentação turística, o turismo de negócios apresenta-se como um potencial devido ao caráter industrial e portuário da cidade, que também desponta para o turismo de eventos. Faz-se necessário o desenvolvimento de políticas efetivas para essas diferentes demandas.

Essa organização da cadeia do turismo municipal apresenta-se como possibilidades para os Empreendimentos Econômicos Solidários (EES), capazes de gerar trabalho e renda associados ao turismo. Pensar uma linha de turismo alternativo solidário que possa ser construída pelo Centro Público de Economia Solidária na cidade de Itajaí e região é um desafio, considerando as condições existentes. Maldonado (2009, p. 31) reforça a possibilidade quando afirma que "os trabalhos na linha do turismo alternativo têm mais possibilidades de bons resultados quando agregados ou beneficiados por sua localização junto a locais receptores de turismo".

Positivamente, quando se trata de economia solidária, Itajaí constitui-se em uma cidade referência, mobilizadora desse potencial. O Fórum Litorâneo organiza e articula os 11 municípios da região da AMFRI e a cidade de Brusque. Fruto desta experiência de impacto regional e de menção nacional está o CEPESI, que atua como um "guarda-chuva", objetivando ser referência para a mobilização, formação e comercialização dos produtos e serviços dos Empreendimentos Econômicos e Solidários.

Enquanto espaço físico, o CEPESI constitui uma loja alternativa, ligada ao Comércio Justo, que recebe turistas durante sua visitação à cidade. Existem poucas ações direcionadas a esse público de forma mais efetiva e direta, o que precisa ser explorado. Considerando que o CEPESI possui uma proposta de trabalho que visa articular os empreendimentos econômicos solidários, de forma autogestionária, o espaço tem o desafio, desde sua constituição, de ser um espaço alternativo e inovador, trabalhando os princípios da economia solidária, o que motiva o estudo de inserção do turismo alternativo solidário, inclusivo e comunitário.

\section{O Centro Público: sua organização e sua produção relacionada ao turismo}

A compreensão do CEPESI e sua organização são necessárias para visualizar as possibilidades do turismo alternativo e solidário nesse espaço.

Os Centros Públicos de Economia Solidária são uma ação de política pública que nasceu da parceria entre a rede de gestores e a Secretaria Nacional de Economia Solidária (SENAES) do Ministério do Trabalho e Emprego. Os Centros Públicos de Economia Solidária abrigam nas suas dependências várias iniciativas e projetos voltados ao fortalecimento da Economia Solidária (ES), sejam governamentais ou não, promovendo a sua integração. Foi estabelecido por meio de Termo da Referência, no qual todos os parceiros deveriam realizar audiência pública para implantação de um Centro Público, visando 
transparência na sua criação. Segundo o Termo de Referência, os Centros Públicos devem construir um Conselho Gestor (CG) com representação majoritária da sociedade civil.

O CEPESI foi criado em 2005 a partir do termo de referência junto a SENAES e fruto da articulação do movimento social ligado à geração de renda e à organização existente dos empreendimentos da cidade, que conquistaram junto à prefeitura municipal este espaço.

Com o desenvolvimento e bons resultados desta organização, hoje o CEPESI situa-se em espaço amplo e moderno com mais de $1500 \mathrm{~m}^{2}$, localizado no centro da cidade, com uma organização estruturada, somando as várias entidades de apoio, governo e empreendimentos. Esse processo de organização possibilitou ao município aprovar um Projeto Ações Integradas de Economia Solidária para o Município de Itajaí, SC, junto à SENAES, que visa ampliar e incrementar a economia solidária nos territórios, fortalecer os empreendimentos existentes e a política de ES.

O CEPESI coloca-se na condição de um forte articulador de toda a região da AMFRI e a cidade de Brusque, fomentando a organização em todos os municípios, visto que boa parte destes têm, através de seus empreendimentos de economia solidária, produtos comercializados no espaço. Em parceria com a Incubadora Tecnológica de Cooperativas Populares (ITCP) da UNIVALI, que articula entre seus trabalhos a incubação do Fórum Litorâneo, bem como a Rede de Políticas Públicas de ES na região, o CEPESI constitui-se em um espaço da comercialização de EES dessa região e mobilização do movimento de EES (UNIVALI, 2009).

O Centro Público de Economia Solidária de Itajaí possui uma oferta de produtos variados, especialmente no artesanato, servindo de atrativo ao turismo. No espaço também se destaca sua oferta variada de confecção, somada à marca Justa Trama, um grupo de consertos e costura, o espaço popular de educação em saúde, com opção de cuidados variados, e o bazar da Cooperfoz. Este é um bazar da Cooperativa de Catadores que comercializa na loja o lixo que é luxo, produtos vindos da reciclagem propiciando fazer a discussão referente ao consumo. Ocorre também a comercialização de produtos orgânicos da
Rede Eco Vida. No CEPESI há auditório para formação e eventos, feira de troca solidária, espaço para exposição de produtos da Associação Quilombola do Morro do Boi, do Núcleo Negro Afrodescendentes Manoel Martins dos Passos, além de área para atendimento aos turistas, informando sobre sua história, oficinas, cursos como o da renda de bilro, atividades que trazem vitalidade ao lugar.

A entidade se caracteriza juridicamente como uma associação de direito privado, composta por conselho de administração, 14 EES associados, cinco entidades de apoio, dois gestores públicos. Possui uma diretoria eleita a cada dois anos e trabalha com comissões (comercialização, projetos, mobilização e marketing, formação). Ela engloba um conjunto de empreendimentos que buscam incluir pessoas, trabalhando seu empoderamento e gerando renda e sustentabilidade. Soma uma gama de indivíduos envolvidos nos empreendimentos com cerca de 130 pessoas diretas, definindo sua missão, visão e estratégias, visando atender os objetivos estabelecidos e os desejos dos associados, bem como trabalhar a autogestão em sua essência.

Sua missão é fomentar a Economia Solidária com articulação, formação e desenvolvimento local sustentável por meio de inclusão social e consciência ambiental. Sua visão é ser referência em Economia Solidária como Centro Público, praticando organizadamente seus princípios.

Objetiva promover os direitos humanos respaldados na solidariedade, na ética e na democracia, bem como promover o desenvolvimento sustentável, com foco nas relações sociais e produtivas, fundamentado nos preceitos de comércio justo e solidário, e com participação dos produtores em todas as fases do processo da cadeia produtiva.

Suas diretrizes e estratégias estão estabelecidas no campo da formação continuada para todos os associados fazem parte do CEPESI, aberto a demais grupos que desejem participar. Há também o trabalho com a articulação do movimento de Economia Solidária junto às redes, fóruns, feiras, conselho, visando fortalecer e ampliar os parceiros e a inserção do Centro Público no movimento. Persegue a sustentabilidade econômica e social, incentivando a construção de redes e cadeias ou a participação dos EES nestas. 
É importante perceber que, em muitos casos, a inserção de um empreendimento na economia solidária articula-se à necessidade econômica e à ação da busca de um mundo melhor. Como demonstra a Associação Nacional de Trabalhadores e Empresas de Autogestão [ANTEAG] (2002, p. 143) "Para muitos, o cooperativismo e a autogestão é um projeto de sobrevivência. Para outros, um projeto de vida. Para o país, um projeto de sociedade". O Centro Público de Economia Solidária trabalha com autogestão na sua organização. Esta se destaca como ponto fundamental em toda a organização da economia solidária. A autogestão é apontada como centralidade para a economia solidária. Cabe olhar as expressões como: empenho, liberdade, participação, colaboração e união. Estas são colocações que os membros envolvidos em processo de produção e comercialização coletiva sempre apresentam.

A verdade é que a prática tende a surpreender a teoria, pois a autonomia dos indivíduos, tão anunciada por alguns esquemas teóricos, é realmente experimentada, mesmo que de maneira frágil e incipiente. A partir daí, a teoria passa a correr atrás dos significados assumidos por essa liberdade vivida. A teoria pode dar conta em boa medida do porquê das mudanças, mas não das próprias mudanças. Porque o novo, mesmo que nunca seja um novo absoluto, traz qualidades que escapam de olhares acostumados a enxergá-los no mundo. (ANTEAG, 2002, p. 42).

O Centro Público, mesmo com toda a sua estrutura, organização e trabalho autogestionário e convivência nos princípios da economia solidária (cooperação, autogestão, solidariedade e atividade econômica), possui também suas fragilidades e dificuldades, tais como sustentabilidade, entraves tributários e fiscais, participação do voluntariado no atendimento ao público, gestão de conflitos, inovação, melhora permanente na qualidade de atendimento e produtos, formação, divulgação, inserção maior no mercado local, empoderamento e fortalecimentos dos EES. Esses temas são trabalhados em suas reuniões, convivência e em formações que permanentemente buscam junto aos parceiros, possibilitar maior aprofundamento na organização e trabalho do CEPESI.

O CEPESI trabalha claramente a característica da economia solidária, pois é intrín- seco a seu processo a autogestão. As decisões são tomadas em reuniões mensais do Conselho Gestor, compostas por um representante de cada associado citado acima. Princípios como cooperação, democracia, solidariedade e respeito à natureza são possíveis de serem identificados em cada grupo associado. $\mathrm{O}$ CEPESI é um marco para o movimento, considerado uma grande conquista pelos seus associados, sendo o turismo alternativo solidário um grande potencial a ser explorado.

\section{As possibilidades do turismo alternativo solidário no CEPESI}

A partir da técnica de interpretação do Discurso do Sujeito Coletivo (DSC) são elencados os resultados da observação da participante, apresentando os pensamentos e falas dos associados e parceiros do CEPESI, suas visões sobre o Centro Público e a economia solidária, sobre turismo e turismo alternativo solidário, além das possibilidades e desejos de articulação da economia solidária ao turismo alternativo solidário.

Quando questionados acerca de como os membros e parceiros identificam o CEPESI e a economia solidária de Itajaí, SC, tem-se destaque para as dificuldades, mas também para o valor do trabalho realizado. Os discursos apontam para:

Uma ideia interessante, mas, sub divulgada tanto por parte do turismo como da população, não tendo uma identificação clara.

O diferencial principal está na comercialização, na organização e gestão compartilhada. Trabalha três eixos: formação, comercialização e mobilização, possuem vários grupos associados, cooperativas e associações.

O CEPESI é tudo de bom, se encontra de tudo e é uma faculdade. O mais importante é o crescimento para as pessoas e as formações. Um local diferente com uma economia diferente que agrega valor a produção local.

Pautado nessa ideia de solidariedade, associação e cooperativismo, pode-se afirmar:

Ao integrar a cooperativa, muitos experimentam pela primeira vez em suas vidas o gozo de direitos iguais para todos, o prazer de poderem se exprimir livremente e de serem escutados e o orgulho de perceber suas opiniões sendo respeitadas, e pensam no destino do coletivo. (SINGER, 2003, p.116). 
Os associados e parceiros do CEPESI descrevem, através do DSC, o turismo como um momento de: "Viver uma experiência diferente, conhecer culturas, lugares, intercâmbio, onde buscamos a similaridade com nosso cotidiano ou lugar".

Em relação ao turismo alternativo solidário, foi preciso trazer à mente vários tipos de turismos alternativos para que se pudesse buscar o conhecimento referente ao turismo de base comunitária ou solidário. O DSC aponta para diversas visões e o desconhecimento sobre o tema:

Não conheço Turismo de Base Comunitária. Interessante, imagino que seja mais segmentado. Conheço um pouco sobre outras áreas de turismo. Ouvi falar de turismo de intercâmbio, observação, ecológico, náutico, aventura e na faculdade (graduação) não tem nada sobre turismo de base comunitária - TBC. Não se conhece sobre tema e deveria poder estudar para CEPESI conhecer e até abrir outra forma de atração turística.

No turismo rural, tem as pousadas residenciais, interessante, se vivencia o turismo. O Turismo de Base Comunitária é uma atividade comunitária. Para Itajaí escapou o tempo e possibilidade de organização pelo seu tamanho atual e outros interesses.

O que o CEPESI faz na organização de seu espaço pode ser mostrado e isso ser um turismo diferente.

Na discussão sobre a recepção do turista e produtos da cidade para agregar à atividade turística, aparece no DSC a questão dos produtos típicos reforçando a necessidade de divulgação:

Turismo é recepção, boa informação para turista, produto com apelo turístico, intercâmbio de saberes e produtos de Itajaí, a lembrancinha que mostre a cultura da cidade. O CEPESI precisa da divulgação, trabalhar o diferencial, todo o conceito do projeto e sua rede de comercialização. Temos muitos produtos similares e deveria usar o potencial para apelo turístico.

Necessita de um folder e de trabalho dentro das agências, pontos turísticos e nas secretarias. O Centro poderia ser uma atração turística, mas precisa de melhor divulgação, a maioria não conhece. O Centro necessita divulgar e estar mais presente em feiras de divulgação.
Necessita de uma divulgação ampla e mais do estado e do governo federal, colocar no calendário nacional as cidades que tem Centro Público, pensar algo com a SENAES, divulgar turisticamente os Centros Públicos e o Comércio Justo.

O CEPESI deveria estar em todos os eventos do Município. Integra participar da Lei de Incentivo à Cultura, estar mais próximo com FITUR.

Ter a ES no roteiro turístico. Valorizar a rede de comercialização que possuem, estar com identidade visual forte, material de divulgação.

O CEPESI, ele aqui e turismo está longe. Poucos conhecem na universidade ou, se perguntar aos servidores dos municípios que estão no CEPESI, poucos conhecem. Nós temos a AMFRI aqui, e talvez fazer uma qualificação com o CEPESI, para se inteirar.

Refletindo se os produtos do Centro Público estão relacionados ao turismo, os sujeitos apontam em seu discurso que o fenômeno turístico existe, mas de forma incipiente no Centro, necessitando ser planejado:

Poderíamos pensar em construir uma gama de produtos que tenha a ver com a cidade, resgate a cultura, ter um cartão, uma etiqueta identificando e divulgação do CEPESI. Colocar no meio turístico seu potencial, trabalhar forte $\mathrm{o}$ artesanato, mas precisa ter uma pessoa para ajudar.

Buscar a criação de brindes e ter apoio de pessoas para criar produtos típicos regionais e outros produtos. Trabalhar produtos corporativos com brindes para hotéis e restaurantes feitos pela ES, parcerias. O artesanato é forte e ser parceiro do roteiro cultural que o Consórcio da AMFRI está montando é uma possibilidade.

Temos uma carência muito grande de achar produtos da cidade, com a marca da cidade, o pouco que tem às vezes tem qualidade ruim. Ampliar os grupos e ter capacidade de criar mais e vender mais, empreender, estudar, conhecer.

Os sócios do Centro destacam a necessidade de formação, debate, estudo e conhecimento sobre o tema. Apontam suas necessidades e apoios desejados, bem como seus sonhos:

Ter assessoria para análise crítica, para pensar em produtos e serviços voltados ao turismo. Proporcionar mais qualificação 
para os artesãos referente aos produtos e acabamentos, tendo os pontos de turismo da região revelado nos produtos.

Trabalhar a rede de comercialização com identificação de produtos de cada cidade, fortalecer a rede de políticas públicas.

CEPESI deve participar mais, tem o conselho de turismo, vir à secretaria conversar, trazer ideias, ser mais proativo. Buscar assessoria de agência de turismo para trabalhar pacotes turísticos, e a comunicação, com divulgação do conceito.

Foi elaborado um plano pela UNIVALI, junto ao DRS de comunicação integrada para o CEPESI e precisa fazer isso acontecer.

Ter formação sobre turismo para levar o conceito do que é o CEPESI para turismo. Formação e capacitação e capacidade também, conhecer bem os grupos que participam.

O CEPESI apresenta-se como uma fonte de geração de renda, que fortalece os princípios da economia solidária, além de convergir com os princípios e a organização do turismo alternativo solidário.

\section{Considerações finais}

As experiências destacadas confirmaram a possibilidade de se buscar um caminho de reflexão sobre o trabalho da economia solidária associada ao turismo alternativo solidário junto ao CEPESI, vislumbrando um novo olhar para o turismo.

Questões como a falta de divulgação das atividades realizadas pelo CEPESI, necessidade de planejamento e de maior identidade da cidade de Itajaí no cenário turístico foram apontadas como deficiências ao desenvolvimento do turismo. Apesar de seu trabalho amplo e com muitas conquistas de políticas públicas no município de Itajaí, faz-se necessário uma maior divulgação do Centro Público de Economia Solidária.

Trabalhar os aspectos de planejamento e formação acerca do turismo alternativo solidário contribuirá na comercialização dos produtos e no atendimento aos diferentes perfis de turistas que chegam ao CEPESI.

É sabido que o turismo alternativo solidário ainda é pouco conhecido e explorado, inclusive nacionalmente. Para que a comunidade compreenda o turismo alternativo soli- dário, recomendam-se debates e capacitações que podem ocorrer no próprio espaço físico do CEPESI, inclusive buscando apoio de entidades e instituições de ensino.

O CEPESI proporciona que os envolvidos sintam-se parte do processo. Proporciona liberdade de expressão acerca de sua gestão, apresentando potencial para tornar-se um espaço educador para o turismo alternativo solidário, reafirmando sua prática da economia solidária. Contudo existe a necessidade de se ampliar e dar continuidade aos estudos, visando ao adequado planejamento desse caminho.

\section{Referências}

ARROYO, J. C. T. Desenvolvimento, natureza e cultura: economia criativa e economia solidária. In: COLÓQUIO CELSO FURTADO SOBRE CULTURA E DESENVOLVIMENTO, 4., 2013, Belém. Anais... Belém: Secretaria da Economia Criativa, Ministério da Cultura, 2013.

ASSOCIAÇÃO DOS MUNICÍPIOS DA FOZ DO RIO ITAJAÍ - AMFRI. Atualização do plano de marketing turístico integrado: PEMTI / COSTA VERDE \& MAR. Itajaí, 2013. Disponível em: <http// www.amfri.org. br>. Acesso em: 2 abr. 2014.

ASSOCIAÇÃO NACIONAL DE TRABALHADORESE EMPRESAS DE AUTOGESTÃO - ANTEAG. Autogestão: construindo uma nova cultura nas relações de trabalho. 2. ed. São Paulo: ANTEAG, 2002.

BARTHOLO, R.; SANSOLO, D. G.; BURSZTYN, I. (Org.). Turismo de base comunitária: diversidade de olhares e experiências brasileiras. Rio de Janeiro: Letras e Imagem, 2009.

BONI, I. M. Desafios para a associação do turismo à economia solidária: a experiência do CEPESI em Itajaí/SC. 2014. 203f. Dissertação (Mestrado em Turismo) - Universidade do Vale do Itajaí, Balneário Camboriú.

BRASIL. Ministério Do Turismo. Marcos conceituais do turismo. Brasília: Mtur, 2010. Disponível em: <http// www.turismo.gov.br>. Acesso em: 20 jun. 2013.

BURSZTYN, I.; BARTHOLO, R.; DELAMARO, M. Turismo para quem? Sobre caminhos de desenvolvimento e alternativas para o turismo no Brasil. In: BARTHOLO, R.; SANSOLO, D. G.; BURSZTYN, I. (Org.). Turismo de base comunitária: diversidade de olhares e experiências brasileiras. Rio de Janeiro: Letras e Imagem, 2009. p. 76-91.

CORIOLANO, L. N. et al. Arranjos produtivos locais do turismo comunitário: atores e cenários em mudança. Fortaleza, CE: Ed. UECE, 2009.

FONTOURA, A. G. da C. Redes de turismo comunitário no Brasil: a experiência da Rede Brasileira de Turismo Solidário e Comunitário (TURISOL). Projeto Bagagem. In: FÓRUM GLOBAL SOBRE TURISMO. FÓRUM SOCIAL MUNDIAL, 2009, Belém. Anais... Belém: FSM, 2009. Disponível em: <http//www.fboms.aspoan.org/ wp-content/uploads/.../TURISOL_AnaGFontoura.dc $>$. Acesso em: 11 maio 2013. 
HALL, C. M. Planejamento turístico: políticas, processos e relacionamentos. São Paulo: Contexto, 2001.

INSTITUTO BRASILEIRO DE GEOGRAFIA E ESTATÍSTICA - IBGE. Censo 2010. Dados sobre as Cidades. Disponível em: <http//www.ibge.gov.br>. Acesso em: 12 jan. 2014.

IRVING, M. de A. Reinventando a reflexão sobre turismo de base comunitária: inovar é possível? In: BARTHOLO, R.; SANSOLO, D. G.; BURSZTYN, I. (Org.). Turismo de base comunitária: diversidade de olhares e experiências brasileiras. Rio de Janeiro: Letras e Imagem, 2009. p. 108-121.

ITAJAÍ. Secretaria Municipal de Turismo Itajaí/SC. III Fórum Itajaiense de Turismo, 153 anos da cidade. 2013. Disponível em: <http//www.itajaí.sc.gov.br>. Acesso em: 10 jan. 2014.

LAKATOS, E. M.; MARCONI, M. A. Fundamentos da metodologia científica. São Paulo: Atlas, 1991.

LEFÈVRE, F.; LEFÈVRE, A. M. C. O discurso do sujeito coletivo: uma nova abordagem metodológica em pesquisas qualitativas. Caxias do Sul, RS: EDUCS, 2000.

MALDONADO, C. O Turismo Rural Comunitário na América Latina. In: BARTHOLO, R.; SANSOLO, D. G.; BURSZTYN, I. (Org.). Turismo de base comunitária: diversidade de olhares e experiências brasileiras. Rio de Janeiro: Letras e Imagem, 2009. p. 25-44.
MOREIRA D. A. O método fenomenológico na pesquisa. São Paulo: Pioneira Thonnson Leaurrnng, 2002.

SCHIOCHET, V. Da democracia a autogestão: economia solidária no Brasil. In: BENINI E. A.; FARIA, M. S.; NOVAES, H. T.; DAGNINO, R. (Org.). Gestão pública e sociedade: fundamentos e políticas públicas de Economia Solidária. São Paulo: Outras Edições, 2012.

SILVA, K. T. P.; RAMIRO, R. C.; TEIXEIRA, B. S. Fomento ao turismo de base comunitária: a experiência do Ministério do Turismo. In: BARTHOLO, R.; SANSOLO, D. G.; BURSZTYN, I. (Org.). Turismo de base comunitária: diversidade de olhares e experiências brasileiras. Rio de Janeiro: Letra e Imagem, 2009. p. 359-373.

SINGER, P. Economia solidária. In: CATTANI, A. D. (Org.). A outra economia. Porto Alegre: Veraz Editores, 2003.

UNIVERSIDADE DO VALE DE ITAJAÍ - UNIVALI. Panorama da Situação Socioeconômica do Centro Público de Economia Solidária de Itajaí (CEPESI). Incubadora Tecnológica de Cooperativas Populares. Itajaí, 2009.

YÁZIGI, E. Saudades do futuro: por uma teoria do planejamento territorial do turismo. São Paulo: Plêiade, 2009.

ZAQUAL, H., Do turismo de massa ao turismo situado: quais as transições? In: BARTHOLO, R.; SANSOLO, D. G.; BURSZTYN, I. (Org.). Turismo de base comunitária: diversidade de olhares e experiências brasileiras. Rio de Janeiro: Letra e Imagem, 2009. p. 55-75. 